
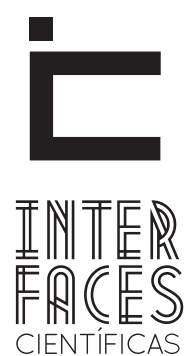

EDUCAÇÃO

\title{
QUALIDADE DA EDUCAÇÃO: CONSENSOS E DISSENSOS ENTRE O DISCURSO OFICIAL E DOS SEUS CRÍTICOS
}

Betisabel Vilar de Jesus Santos ${ }^{1}$

\section{RESUMO}

O debate sobre a qualidade constitui-se em um dos principais desafios da educação na contemporaneidade, uma vez que aprender circunscreve-se como direito do cidadão e instrumento fundamental no combate às desigualdades ainda existentes em nosso país. Embora haja concordância quanto à necessidade de assegurar aos cidadãos uma educação e um sistema de ensino de qualidade, nas políticas públicas da educação brasileira, o sentido atribuído à qualidade e as ações voltadas à sua promoção, são muitas vezes objeto de críticas contundentes, daí, torna-se necessário verificar a lógica que fundamenta o discurso oficial da qualidade da educação, identificando o contexto social do qual e com o qual se fala e as críticas a ele feitas.

\section{PALAVRAS CHAVE}

Qualidade da Educação. Políticas Públicas. Política Educacional. Educação Básica.

\section{ABSTRACT}

The debate over the quality constitutes one of the main challenges of education in the present, since learning is limited as citizens' rights and fundamental tool in combating inequalities that still exist in our country. Although there is agreement on the need to ensure that citizens have an education and a system of quality education in the public policies of the Brazilian education, the meaning attributed to the quality and the actions of their promotion, are often the subject of sharp criticism, hence, becomes necessary to check the logic that underlies the official discourse of the quality of education, identifying the social context in which and with which we speak and the criticism he made.

\section{KEYWORDS}

Quality of Education. Public Policy. Education Policy. Education. 


\section{RESUMEN}

El debate sobre la calidad, constituye uno de los principales retos de la educación en el presente, ya que el aprendizaje se limita a los derechos de los ciudadanos y a una herramienta fundamental en la lucha contra las desigualdades que aún existen en nuestro país. Aunque no exista un acuerdo sobre la necesidad de garantizar que los ciudadanos tengan una educación y un sistema de educación de calidad en las políticas públicas de la educación brasileña, el significado atribuido a la calidad y las acciones de su

\section{INTRODUÇ̄̃O}

Tema recorrente no debate educacional, a questão da qualidade constitui-se em um dos principais desafios da educação na contemporaneidade, uma vez que aprender circunscreve-se como um direito do cidadão e instrumento fundamental no combate às desigualdades ainda existentes em nosso País.

A emergência desse debate é resultante das transformações que se processaram na sociedade contemporânea, que ao intensificar o processo de globalização econômica, política e cultural e promover uma revolução tecnológica originou a chamada "sociedade do conhecimento", desencadeando, como sinaliza SHIROMA (2000), a preocupação com a qualidade da educação, entendida como instrumento de acesso dos cidadãos aos códigos da modernidade.

Embora haja concordância quanto à necessidade de assegurar aos cidadãos uma educação e um sistema de ensino de qualidade, o sentido de que se reveste é diverso, posto que depende de onde falam os sujeitos, dos seus interesses e valores, bem como, do conteúdo por estes defendidos. Neste sentido, a qualidade assume duas características básicas: é contextual porque tem relação direta com as práticas promoción, son a menudo objeto de fuertes críticas, por lo tanto, se hace necesario revisar la lógica que subyace en el discurso oficial de la calidad de la educación, identificando el contexto social del cual y con el cual hablamos y las críticas que han sido hechas..

\section{PALABRAS CLAVE}

Calidad de la Educación. La Política Pública. La política Educativa. La Educación. sociais que respaldam seu processo de construção; e, ao mesmo tempo é contingente, pois resulta de contextos dinâmicos e mutáveis e ao mobilizar sujeitos com trajetórias e demandas particulares, provocam diferentes fixações de sentidos.

A complexidade de que se reveste o tema não possibilita a adoção de um único e totalizador conceito da qualidade em educação, capaz de resumi-la em um único atributo. Para efeito desse estudo, adotou-se o enfoque recorrentemente utilizado por organizações da sociedade civil e nos documentos oficiais, a exemplo daquele expresso no Caderno 2 do Programa Nacional de Fortalecimento dos Conselhos Escolares.

[...] 'escola de qualidade' é aquela que contribui para a formação dos estudantes nos aspectos culturais, antropológicos, econômicos e políticos, para o desempenho de seu papel de cidadão no mundo, tornando-se, assim, uma qualidade referenciada no social. Neste sentido, o ensino de qualidade está intimamente ligado à transformação da realidade. (In. Conselho Escolar e a aprendizagem na escola, 2004, p. 31)

Desse modo, a política e as ações que dela resultam são objeto de críticas contundentes, motivo pelo 
qual torna-se necessário verificar a lógica que fundamenta o discurso oficial da qualidade da educação básica, identificando o contexto social do qual e com o qual se fala e as críticas a ele feitas.

Para contextualizar os discursos em torno da qualidade da educação, foi procedido ao estado do conhecimento, tendo como referência as bases de dados da Associação Nacional de Pós-Graduação e Pesquisa em Educação (Anped), no período de 2009 a 2011 e o banco de teses da Coordenação de Aperfeiçoamento de Pessoal de Nível Superior (Capes), no período de 2007 a 2011. Na Anped, foram consultados os Grupos de Trabalho Estado e Política Educacional (GT 5) e Sociologia da Educação (GT14). Já com relação ao Banco de Dados da Capes foram localizadas, no período estudado, duas dissertações. Além das citadas fontes de pesquisa, foram consultados artigos que tratam da temática proposta.

Espera-se com o presente artigo contribuir com uma maior compreensão da temática na perspectiva do governo e dos críticos, buscando as aproximações e distanciamentos no uso do significado da qualidade da educação.

\section{CENÁRIO INTERNACIONAL DESENCADEADOR DO DEBATE SOBRE A QUALIDADE DA EDUCAÇÃO}

Em que pese não haja consenso sobre o sentido de qualidade atribuído à educação, a literatura educacional e mais recentemente os discursos oficiais sinalizam para uma concepção de educação que além de assegurar o acesso, possibilita a inserção social, econômica e política dos cidadãos. Esta concepção foi se constituindo nos últimos 30 anos, sobretudo, em função das transformações que se processam no contexto econômico, social, cultural e político em que se insere a sociedade atual.

No Brasil, como em outros países em desenvolvimento, a crise desencadeada na década de 1980 provocou a necessidade de proceder a reformas de modo a assegurar a estabilidade econômica, e, uma vez que o crescimento sustentável exige sociedades integradas, as questões sociais ganham centralidade, tornando-se objeto de políticas e investimentos na área. Nesse cenário, a educação ganhou destaque, por haver um entendimento de que a falta de educação básica para significativas parcelas da população constituía impedimento para que a sociedade enfrentasse esses problemas com vigor e determinação, respondendo assim, às necessidades de desenvolvimento expressas no crescimento econômico e na integração social.

As mudanças processadas na educação resultaram tanto de pressões internas - provocadas pelo processo de redemocratização do País -, quanto dos compromissos assumidos por seus representantes em eventos promovidos por organismos internacionais, a exemplo da Conferência Mundial sobre Educação para Todos, realizada em 1990 em Jontien (Tailândia). Esse evento teve por finalidade criar um contexto político favorável para a educação; orientar as políticas educacionais para fortalecer a educação básica; proporcionar maior atenção aos processos de aprendizagem; e buscar satisfazer as necessidades fundamentais de aprendizado. A viabilização de tais ações resultou em um documento no qual os países se comprometeram a efetivar políticas educacionais voltadas à satisfação das necessidades básicas de aprendizagem de crianças, jovens e adultos (TAILÂNDIA, 1990).

Merece destaque ainda o Promedlac IV, reunião de ministros de Educação convocados pela Unesco 
para analisar o desenvolvimento do Projeto Principal de Educação para a América Latina e o Caribe. Aconteceu em Quito, em 1991, sendo considerado por organismos internacionais como um marco no âmbito da política de educação na década de 90. CASSUS (2001), em uma referência à declaração emanada dessa reunião, aponta que o esgotamento das estratégias tradicionais dos sistemas educativos da região e a dificuldade de conciliar quantidade e qualidade requerem ações voltadas a responder aos desafios da transformação das atividades de produção, da equidade social e da democratização política e suscita uma profunda transformação da gestão tradicional.

Eventos anteriores ou posteriores a estes mantiveram aceso o debate sobre os grandes problemas enfrentados pelos países em desenvolvimento. No âmbito da educação destacam-se como principais deliberações: necessidade de promover uma profunda transformação da gestão tradicional, com a abertura do sistema à participação de novos atores na tomada de decisões; vasto processo de descentralização e deslocamento da ênfase da quantidade para a qua- lidade; e ênfase nas ações voltadas à melhoria dos níveis de qualidade das aprendizagens, através da criação de sistemas nacionais de avaliação e da preocupação com a escola e seus processos.

Nesse período, organismos internacionais, a exemplo da Unesco, produziram estudos com a finalidade de subsidiar as reformas da educação nos países em desenvolvimento, adequando-as ao contexto em que estavam inseridas. Também foram apresentadas alternativas para viabilizar a implementação dessas reformas (SHIROMA, 2000).

No caso do Brasil, a nova realidade fez emergir o debate sobre a qualidade da educação ofertada e resultou na adoção de medidas que constituíram o arcabouço do que se denominou reforma educacional brasileira que teve na gestão democrática, obrigatoriedade, qualidade do ensino e descentralização das políticas educacionais, ações centrais da intervenção estatal na Educação Básica e importantes instrumentos para assegurar a eficiência do sistema de ensino (SHIROMA, 2000).

\section{CENÁRIO INTERNOE O DEBATE DA QUALIDADE DA EDUCAÇ̃̃O}

O processo de discussão das mudanças no âmbito educacional para além das disputas travadas entre os sujeitos que participaram da sua elaboração e das práticas sociais que as constitui tem, no marco legal, forte aporte na fixação discursiva do sentido de qualidade da educação.

Esse processo foi iniciado com a promulgação da Constituição Federal de 1988 (BRASIL, 1988a) que ao estabelecer um conjunto de direitos sociais desencadeou na sociedade novas expectativas de atendimento que demandaram a ampliação da atuação do Esta-

do. No âmbito da educação, a Carta Magna definiu: "A educação, direito de todos e dever do Estado e da família, será promovida e incentivada com a colaboração da sociedade, visando ao pleno desenvolvimento da pessoa, seu preparo para o exercício da cidadania e sua qualificação para o trabalho". (Art. 205).

A Constituição também definiu os princípios que nortearão a educação no País, dentre os quais se destacam: igualdade de condições para o acesso e permanência na escola; valorização dos profissionais do ensino, garantidos, na forma da lei, planos de carreira 
para o magistério público, com piso salarial profissional; ingresso exclusivamente por concurso público de provas e títulos; e garantia de padrão de qualidade.

O avanço da legislação no sentido de assegurar a conquista da qualidade da educação ganhou reforço em 1996, com a aprovação da Lei de Diretrizes e Bases da Educação Nacional (LDB), documento que expressa consenso sobre o que se espera da educação no País. No inciso IX do artigo $3^{\circ}$, se assegura a garantia do padrão de qualidade e nas Disposições Gerais se estabelece a observância dos aspectos qualitativos sobre os quantitativos nos processos de avaliação. Este preceito é também reafirmado no inciso IX do artigo $4^{\circ}$ quando proclama padrões mínimos de qualidade de ensino, definidos como a variedade e quantidade mínimas, por aluno, de insumos indispensáveis ao desenvolvimento do processo de ensino e aprendizagem.

Em cumprimento aos preceitos da qualidade da educação para todos, estabelecido pela LDB, foram promulgadas em 1998 e referendadas em 2010 as Diretrizes Curriculares Nacionais para a Educação Básica $(D C N)^{1}$, documento que explicita a política curricular do Estado brasileiro; reafirma ser a oferta de educação de qualidade o objetivo principal do sistema educacional brasileiro; e reconhece ser este um direito inalienável de todos os cidadãos.

Nas DCNs, é também definida a concepção de qualidade assumida pelo discurso oficial: a qualidade social da educação. Conforme explicitado no referido documento, a garantia do padrão de qualidade se consubstancia pelo

[...] pleno acesso, inclusão e permanência dos sujeitos das aprendizagens na escola e seu sucesso, com re-

\footnotetext{
1 As DCNs, “conjunto de definições doutrinárias sobre princípios, fundamentos e procedimentos na Educação Básica (...) que orientarão as escolas brasileiras dos sistemas de ensino, na organização, na articulação, no desenvolvimento e na avaliação de suas propostas pedagógicas" (Brasil, 2010a) foram referendadas pelo Parecer CNE/CEB n. ${ }^{0} 7 / 2010$ de 7 de abril de 2010 e da Resolução CNE/CEB n. ${ }^{\circ}$ 4, de 13 de julho de 2010.
}

dução da evasão, da retenção e da distorção de idade/ ano/série, resulta na qualidade social da educação, que é uma conquista coletiva de todos os sujeitos do processo educativo (Brasil, 2010a, p. 62).

Conforme LOPES apud MATHEUS (2011), a concepção de qualidade social atrai um grande número de adeptos e não destitui a qualidade de sua condição de significante, pois social, por mais que tenha limites de significação contextualmente construídos, também é amplo em significados, podendo congregar diversas demandas.

Matheus (2011) também explicita que a concepção da qualidade social da educação não constitui pensamento recorrente na produção oficial, aparecendo pela primeira vez no texto das DCN e nos documentos que a ele se seguiram.

O Plano Nacional de Educação (PNE), instituído para vigorar no período de 2001 a 2010, foi elaborado com a participação de associações e entidades de educadores num processo de discussão democrática e configurou-se como projeto de qualidade da educação brasileira ao direcionar suas ações para melhoria da qualidade do ensino em todos os níveis; redução das desigualdades sociais e regionais no tocante ao acesso e à permanência, com sucesso, na educação pública; democratização da gestão do ensino público.

Como desdobramento do PNE, foi instituído o Plano de Desenvolvimento da Escola (PDE). Em ambos há também referência à concepção de qualidade social como norteadora da política educacional do Governo Federal.

Para viabilizar os preceitos da qualidade da educação, definidos na legislação, o Governo Federal implementou uma série de ações, a exemplo da criação dos sistemas nacionais de avaliação em larga escala, em todos os níveis e modalidades; do Programa Dinheiro Direto na Escola (PDDE) (1995)²; do Fundo de Fortale-

\footnotetext{
$2 \quad 0$ PDDE tem por finalidade prestar assistência financeira às
} 
cimento da Escola (Fundescola) (1997) ${ }^{3}$, que instituiu um Programa de Capacitação e Fonte de Consultas para os Dirigentes Municipais de Educação (Prasem)4; do Programa Nacional de Capacitação de Conselheiros Municipais de Educação - Pró-Conselho (2003) do Fundo de Manutenção e Desenvolvimento da Educação Básica e de Valorização dos Profissionais da Educação (Fundeb) (2007) ${ }^{6}$; do Programa de Apoio aos Dirigentes Municipais de Educação (Pradime) (2006) 7 . Tais políticas e programas têm por finalidade assegurar a elevação da qualidade da educação e ganham consistência com a produção de documentos voltados a subsidiar os diversos segmentos que integram o processo educativo na melhoria dos indicadores de qualidade. Estas mudanças ocorrem no âmbito do currículo, da formação dos professores e da melhoria dos livros didáticos.

Werle (2011) destaca a relevância dos mecanismos de financiamento do ensino declarados na Constituição (1988) e na LDB (1996), como forma de assegurar os recursos necessários à viabilização do cumprimento da obrigatoriedade, melhoria da qualidade do ensino, qualificação da Educação Básica, definição de um

escolas públicas da educação básica para melhoria da infraestrutura física e pedagógica, reforçar a gestão escolar e a elevação dos índices de desempenho da educação básica.

30 programa do Fundo Nacional de Desenvolvimento da Educação (FNDE/MEC), direcionado às regiões Norte, Nordeste e Centro-Oeste, tem por finalidade promover ações voltadas à melhoria da qualidade das escolas do ensino fundamental, por meio da oferta de serviços, produtos e assistência técnico-financeira inovadores que focalizam o ensino-aprendizagem e as práticas gerenciais das escolas e secretarias de educação.

40 Prasem tem por finalidade subsidiar os gestores na compreensão das mudanças na legislação que tratada educação.

50 Pró-Conselho tem por finalidade é subsidiar uma atuação eficiente dos conselheiros municipais de educação.

6 Programa criado pela Emenda Constitucional no 53/2006 e regulamentado pela Lei $n^{0} 11.494 / 2007$ e pelo Decreto $n^{0} 6.253 / 2007$, em substituição ao Fundo de Manutenção e Desenvolvimento do Ensino Fundamental e de Valorização do Magistério - Fundef (1998 a 2006), tem por finalidade financiar todas as etapas da educação básica, destinando recursos às regiões nas quais o investimento por aluno seja inferior ao valor mínimo fixado para cada ano. Ou seja, o Fundeb tem como principal objetivo promover a redistribuição dos recursos vinculados à educação.

$7 \quad 0$ Pradime tem por finalidade fortalecer e apoiar os dirigentes da educação municipal na gestão dos sistemas de ensino e das políticas educacionais, contribuindo assim, para o avanço em relação às metas e aos compromissos do Plano Nacional de Educação (PNE) e do Plano de Desenvolvimento da Educação (PDE). valor por aluno e valorização do professor, das escolas e da educação.

No contexto das medidas voltadas à promoção da qualidade da educação, a partir da década de 1980 manifestaram-se as primeiras iniciativas por parte do MEC no sentido de implantar sistemas centralizados de avaliação da educação no País, com a finalidade de detectar os problemas incidentes no ensino, definir ações para corrigi-los e subsidiar a formulação de políticas educacionais. Neste sentido, foi instituído o Sistema de Avaliação da Educação Básica (1990), o Exame Nacional do Ensino Médio (Enem) (1998), o Exame Nacional de Cursos (Provão) (1995) posteriormente transformado em Exame Nacional de Desempenho de Estudantes (Enade) (2004) e que passou a integrar o Sistema Nacional de Avaliação da Educação Superior (Sinaes).

O Saeb, um dos mais antigos sistemas de avaliação educacional no Brasil, é de responsabilidade do Instituto Nacional de Estudos e Pesquisas Educacionais e, desde sua ampliação, foi sendo aperfeiçoado em termos técnicos e metodológicos. Através de aplicação de provas entre os alunos concluintes de cada uma das etapas da Educação Básica, busca fornecer indicadores do nível de aprendizagem destes e retratar as condições de aprendizagem oferecidas, de modo a subsidiar a definição das políticas públicas para educação.

Posteriormente, foi inserida a Prova Brasil que ao estabelecer a escala de proficiência permite às escolas e aos sistemas de ensino identificar as dificuldades enfrentadas pelos alunos e traçar metas voltadas à superação destas. A partir de 2007 o sistema foi reavaliado e houve a inserção do Índice de Desenvolvimento da Educação Básica (Ideb), que reúne em um só indicador de qualidade da educação o fluxo escolar e as médias de desempenho na Prova Brasil. 0 resultado do Ideb, divulgado por escola, município, Estado e País torna-se critério para que as escolas sejam consideradas prioritárias para receber assistência técni- 
ca e financeira por meio do Plano de Desenvolvimento da Escola (PDE-Escola).

Críticas têm sido feitas ao processo de avaliação em larga escala, dentre outros por: circunscrever o foco da avaliação no desempenho da escola, não avaliando o impacto da condição das famílias na performance escolar; sustentar que a melhoria do desempenho dos educandos ocorre a partir da premiação de professores; desconsiderar as disparidades regionais e entre campo e cidade; imprimir um caráter estritamente instrumental à questão da qualidade. Ainda assim que adotada tardiamente pelo Brasil, a avaliação educacional é uma tendência internacional.

\section{CONCEPCÕ̃ES DE QUALIDADE}

Os sentidos de qualidade que tem permeado o campo educacional assumem caráter contingencial à medida que refletem o contexto em que foram produzidos e legitimados.

Autores como Gusmão (2009) e Matheus (2011) estabelecem uma cronologia que permite identificar como ao longo do tempo foi se constituindo o conceito de qualidade da educação. As citadas autoras identificam quatro fases, a saber:

A primeira fase tem início nos anos de 1970 prolongando-se até os anos de 1980. Nessa fase, o sentido da qualidade estava associado à universalização do acesso à escola.

Na década de 1980, passou a vigorar o segundo significado de qualidade, momento em que, atingida a quase universalização do Ensino Fundamental, passou-se a utilizar o argumento do alto mais ineficaz investimento em educação. Nesse cenário, a ênfase deslocou-se da expansão do acesso à escola, para a permanência. Campos, citado por Gusmão (2009)
Convém ressaltar que nos últimos anos o Ministério da Educação vem adotando uma postura mais participativa na definição de políticas para educação através de parceiras com relevantes instituições científicas, representativas dos segmentos que integram o sistema educacional brasileiro e dos movimentos sociais, a exemplo da Associação Nacional dos Dirigentes das Instituições Federais de Ensino Superior (Andifes), Conselho Nacional de Secretários de Educação (Consed), União Nacional dos Dirigentes Municipais de Educação (Undime), União Nacional dos Estudantes (UNE), União Brasileira dos Estudantes Secundaristas (Ubes) e Confederação Nacional dos Trabalhadores em Educação (CNTE).

identificam esta década como a do "consenso" nacional em torno da necessidade de melhoria da qualidade da educação. Não bastava entrar na escola, era preciso permanecer nela.

Ainda conforme Gusmão (2009), a existência de crianças e jovens fora da escola devia-se à reprovação e à evasão escolar. Nesse caso, superado esse problema, seria alcançada a qualidade.

No tocante à aplicação dos princípios da qualidade total à educação traz para o sistema de ensino a lógica do mercado, associando a qualidade na educação à eficiência e à produtividade.

Os defensores da Qualidade Total entendem que a excelência gerencial nas empresas pode contribuir de maneira significativa para a melhoria do ensino no Brasil, bastando, para tal, que sejam integrados os princípios da Gestão da Qualidade Total à cultura da organização, ao dia-a-dia das pessoas e dos processos organizacionais. 
Essa concepção foi objeto de crítica, sobretudo por parte dos educadores marxistas por tratar a educação como mercadoria, imprimindo-lhe a lógica do mercado e, na medida em que assim procede, o "produto" torna-se o aspecto mais relevante da prática educativa. Para Gentilli (1994), a relação entre educação e setor produtivo tende a alargar as desigualdades já existentes.

O terceiro significado de qualidade aparece recentemente vinculado às temáticas da justiça social, inclusão social e cultural e formação do cidadão crítico. Propugna uma qualidade da educação voltada à emancipação dos sujeitos sociais denominada como educação emancipadora. Um conceito possível de escola de qualidade social é

aquela que atenta para um conjunto de elementos e dimensões socioeconômicas e culturais que circundam o modo de viver e as expectativas das famílias e de estudantes em relação à educação; que busca compreender as políticas governamentais, os projetos sociais e ambientais em seu sentido político, voltados para o bem comum; que luta por financiamento ade- quado, pelo reconhecimento social e valorização dos trabalhadores em educação; que transforma todos os espaços físicos em lugar de aprendizagens significativas e de vivências efetivamente democráticas. (SILVA, 2009, p.225)

Charlot citado por Gusmão (2009) afirma que essa é uma noção "tipicamente brasileira”. Aponta também que

\footnotetext{
"Qualidade social da escola" é uma noção estranha. Com efeito, do ponto de vista sociológico, cada sociedade tem uma escola que, por definição, condiz com ela. Portanto, tem uma escola que apresenta a "qualidade social”, de que ela precisa. (CHARLOT, 2005, p. 40).
}

Como já assinalado, embora não se possa falar de uma educação de qualidade em si, há certa hegemonia quanto à construção da qualidade social da educação, que a vincula a adequadas condições funcionamento das escolas, valorização docente, gestão democrática, articulação com a comunidade, efetiva eficácia da aprendizagem dos alunos e avaliação dos processos.

\section{CONSIDERAÇÕES FINAIS}

As ideias reunidas neste artigo tiveram por finalidade contribuir para ampliação do debate acerca da qualidade da educação.

Por se tratar de fenômeno complexo, que envolve muitas dimensões, o conceito de qualidade requer a compreensão da variedade e quantidades mínimas de insumos necessários ao desenvolvimento do processo de ensino-aprendizagem; dos processos que o envolve e dos seus resultados representados pelo desempenho do aluno (paradigma utilizado pela Unesco). Tais aspectos devem ser analisados de forma articulada com as expectativas e concepções acerca do que deve ser a escola.
Ainda que não haja consensos em torno da questão, depreende-se das concepções aqui apresentadas que o discurso oficial está mais próximo daquele preconizado pelas entidades científicas, pelas instituições que congregam segmentos organizados da educação e da sociedade civil.

Convém reforçar que a educação republicana se concretiza através da legislação educacional, bem como das estratégias de avaliação, controle e regulação dos sistemas educacionais. Observa-se que a mudança de enfoque em direção à priorização da qualidade da educação ganhou fôlego a partir da promulgação da Constituição de 1988 e da legislação produzida posteriormente. 
É necessário avançar mais na descentralização destes sistemas, combinada com sistemas compensatórios efetivos para corrigir desigualdades de recursos financeiros e pedagógicos entre as escolas.

Apesar dos avanços, a discussão a respeito dessa questão, pela complexidade de que se reveste, ainda precisa ser mais aprofundada. No foco deste debate as escolas precisam ser ouvidas e ouvir, para que desse modo possam reduzir os efeitos negativos das condições sociais dos alunos.

\section{REFERÊNCIAS}

AZEVEDO, Janete. Educação como política pública. São Paulo: Autores Associados, 1997. (Coleção Polêmicas do Nosso Tempo).

BRASIL. Assembléia Nacional Constituinte. Constituição Federal, de 5 de outubro de 1988. Brasília, 1988a. Disponível em: www.planalto.gov.br/ccivil_03/constituicao/constituicao.htm. Acesso: 10 jul. 2012.

BRASIL. Parecer CNE/CEB nº 7/2010, aprovado em 7 de abril de 2010, institui as Diretrizes Curriculares Nacionais Gerais para a Educação Básica. Disponível em: http://portal.mec.gov.br/index.php?option=com_content\& view=articleqid=12992: diretrizes-para-a-educacao-basica\&catid=323. Acesso: 10 jul. 2012.

BRASIL. Lei de Diretrizes e Bases da Educação Nacional: Lei n. 9.394/1996. Disponível em: http://www.mec. gov.br/legis/default.shtm. Acesso: 18 set. 2012.

BRASIL. Lei de Diretrizes e Bases da Educação Nacional Lei $\mathbf{n}^{\mathbf{0}} \mathbf{1 0 . 1 7 2}$, de 9 de janeiro de 2001. Institui o Plano Nacional de Educação (PNE). Brasília, 2001b. Disponível em: portal.mec.gov.br/arquivos/pdf/pne.pdf. Acesso: 10 jul. 2012.

BRASIL. Lei de Diretrizes e Bases da Educação Nacional Lei no 11.494, de 20 de junho de 2007. Regulamenta o Fundo de Manutenção e Desenvolvimento da Educação Básica e de Valorização dos Profissionais da Educação (Fundeb). Brasília, 2007. Disponível em: www.planalto.gov.br/ccivil_03/_ato2007-2010/.../L11494.htm. Acesso: 10 jul. 2012

BRASIL. Lei de Diretrizes e Bases da Educação Nacional Plano Decenal de Educação para Todos. Brasília, 1993. Disponível em:www.educabrasil.com.br/eb/dic/dicionario.asp?id=91. Acesso 18 set. 2012.

BRASIL. Lei de Diretrizes e Bases da Educação Nacional 0 Plano de Desenvolvimento da Educação (PDE). Razões, Princípios e Programas. Brasília, 2007. Disponível em:portal.mec.gov.br/arquivos/livro/index.htm. Acesso em 18 set. 2012. 
BRASIL. Lei de Diretrizes e Bases da Educação Nacional Programa de Apoio aos Dirigentes Municipais de Educação (Pradime). Brasilia. Disponível em: http://portal.mec.gov.br/index.php?ltemid=447\&id=219\&option=c om_content\&view=article. Acesso 10 jul. 2012.

BRASIL. Lei de Diretrizes e Bases da Educação Nacional Programa Dinheiro Direto na Escola - PDDE. Brasília. Disponível em: portal.mec.gov.br/index.php/?option=com_content\&view...id... Acesso: 18 fev. 2012.

BRASIL. Lei de Diretrizes e Bases da Educação Nacional Programa Nacional de Capacitação de ConseIheiros Municipais de Educação - Pró-Conselho. Brasília. Disponível em: http://portal.mec.gov.br/index. php?option=com_content\&view=article\&id=251\&ltemid=470. Acesso 23 set. 2012.

BRASIL. Lei de Diretrizes e Bases da Educação Nacional Programa Nacional de Fortalecimento dos Conselhos Escolares. Caderno 2 - Conselho Escolar e a Aprendizagem na Escola. Brasília. Disponível em:http:// portal.mec.gov.br/seb/arquivos/pdf/Consescol/ce_cad2.pdf. Acesso: 10 jul. 2012.

CARVALHO, Rosângela Tenório de. Educação Republicana e Qualidade Social da Educação. In: 34a Reunião Anual da ANPED. Disponível em: 34 reuniao.anped.org.br/ Acesso em: 18 set. 2012.

CASSUS, Juan. A Reforma Educacional na América Latina no contexto de globalização. In. Cadernos de Pesquisa, $n^{0}$ 114, novembro/2001. Disponível em: www.scielo.br/pdf/cp/n114/a01n114.pdf. Acesso: 20 fev. 2008.

DECLARAÇÃO Mundial sobre Educação para Todos. Jontien, Tailândia, 1990.

GENTILLI, P.; SILVA, T. T. (orgs.). Neoliberalismo, qualidade total e educação. Rio de Janeiro: Vozes, 1994.

GUSMÃO, Joana Borges Buarque de. A Construção do Tema da Qualidade da Educação no Brasil. Disponível em: www.anpae.org.br/congressos_antigos/simposio2009/153.pdf. Acesso: 18 set. 2012

MATHEUS, Danielle dos Santos. Educação de Qualidade: $\mathbf{O}$ discurso das Diretrizes Curriculares Nacionais para a Educação Básica. Disponível em:www.anped.org.br/app/webroot/34reuniao/.../GT12-61\%20int.pdf. Acesso: 18 set. 2012

SILVA, Maria Abádia da. Qualidade Social da Educação Pública: algumas aproximações. In: Cad. Cedes, Campinas, vol. 29, n. 78, p. 216-226, maio/ago. 2009. Disponível em: http://www.cedes.unicamp.br. Acesso: 10 jul. 2012

SHIROMA, Eneida Oto et al. Política educacional. Rio de Janeiro: DP\&A, 2000.

WERLE, Flávia Obino C. Políticas de avaliação em larga escala na educação básica: do controle de resultados à intervenção nos processos de operacionalização do ensino. Disponível em: http://www.scielo.br/pdf/ ensaio/v19n73/03.pdf. Acesso: 18 set. 2012 
Recebido em: 7 de agosto de 2013 Avaliado em: 19 de agosto de 2013 Aceito em: 28 de agosto de 2013

1 Doutoranda em Educação pela PUCRS/UNIT. Professora da Universidade Tiradentes-UNIT. Email: betisabel_villar@unit.br.

Interfaces Científicas - Educação • Aracaju • V.2 • N.1 • p. 71-81 • out. 2013 • www.periodicos.set.edu.br 